\title{
AS DUAS NATUREZAS DE LÉVI-STRAUSS
}

Tradução de Estela Abreu

Ninguém ignora o papel crucial que tem na obra de Claude Lévi-Strauss a oposição contrastiva entre natureza e cultura: ele a utiliza em contextos tão diversos e com finalidades tão numerosas que, para muitos, ela chegou a encarnar uma das características de sua maneira de pensar. Sabe-se também que Lévi-Strauss atribui a Rousseau o mérito de ter, na prática, fundado o campo da etnologia quando inaugurou, no Discours sur l'origine et le fondement de l'inégalité [Discurso sobre a origem e o fundamento da desigualdade], a reflexão sobre os vínculos possíveis entre esses dois campos de fenômenos (Lévi-Strauss, 1973: 46-47). Isso significa que o problema da tensão entre natureza e cultura não está apenas no cerne da antropologia estrutural, mas é o que define, aos olhos de seu fundador, o campo estudado pela etnologia, graças ao qual ela pode reivindicar uma autonomia entre as outras ciências humanas. Porém, o status desse par conceptual não é fácil de captar em Lévi-Strauss: ao mesmo tempo ferramenta de análise, cena filosófica dos primórdios e antinomia a superar, ele é revestido pelo autor de uma pluralidade de significados, às vezes contraditórios, que tornam sua utilização altamente produtiva e sua interpretação difícil. No ensejo de esclarecer a questão, este texto se apresenta como um exame crítico e uma homenagem. Porque só avançamos na via escolhida por cada um de nós graças aos progressos conquistados pelas gerações anteriores e, sob esse aspecto, ninguém duvida que o século XX, em antropologia, ficará como o século de Lévi-Strauss, a tal ponto suas ideias, mesmo quando rejeitadas, marcaram vigorosamente o conceito que se tem dessa ciência, de seu objeto e de seus métodos. Minha dívida para com ele é ainda maior, por razões tanto pessoais quanto intelectuais: entre estas, figura em primeiro lugar o estímulo para me dedicar ao assunto deste ensaio - as relações de continuidade e de descontinuidade entre natureza e cultura -, que logo se tornou, graças a ele, o principal eixo de minhas reflexões e de minha atividade profissional. Mas, para construir com segurança em bases sólidas, é preciso também sondar os alicerces, fazer um plano, rearrumar, às vezes, sua distribuição. O texto que se segue tem apenas esta ambição. 
Foi na Conferência Gildersleeve, pronunciada em 1972 nos Estados Unidos, com o título de Structuralism and ecology [Estruturalismo e ecologia], que Lévi-Strauss mais explicitou sua concepção do respectivo papel das operações do espírito e das determinações ecológicas no trabalho que o pensamento mítico efetua quando organiza, em sistemas significantes, certos elementos do meio natural (Lévi-Strauss, 1972). Tratava-se, para ele, de responder, no local de origem, às acusações de idealismo que lhe haviam feito antropólogos norte-americanos que atribuíam às pressões exercidas numa sociedade pelo meio ambiente, e às respostas adaptativas que ela oferecia, a origem e a causa da maioria de suas especificidades culturais. Retomando uma argumentação já apresentada em 0 pensamento selvagem, Lévi-Strauss insistia em mostrar que não há nada de automático nem de previsível no modo como uma sociedade seleciona este ou aquele aspecto de seu hábitat para atribuir-lhe um significado particular e integrá-lo em suas construções míticas. Pois muitas vezes culturas vizinhas identificam em um mesmo animal, ou mesma planta, características pertinentes completamente diferentes, tanto como podem atribuir uma função simbólica idêntica a espécies que pertencem a gêneros e, até, a reinos diferentes. $O$ aspecto arbitrário que comanda as escolhas dos traços distintivos atribuídos a tal ou qual componente dos ecossistemas locais é, entretanto, temperado pelo fato de esses traços estarem organizados em sistemas coerentes, que podem ser apreendidos como os resultados decorrentes de transformações de um pequeno número de regras. Em suma, se mitos provenientes de tribos próximas podem usar para um mesmo fim propriedades inteiramente distintas da fauna e da flora, a estrutura desses mitos nem por isto é aleatória, e se organiza segundo os efeitos refletidos em espelho de inversão e de simetria.

Como era esperado, a Conferência Gildersleeve não conseguiu convencer os materialistas norte-americanos quanto ao bem-fundado da análise estrutural, e até provocou a célebre controvérsia entre Lévi-Strauss e Marvin Harris, então professor na Universidade de Columbia e figura de proa da ecologia cultural (Harris, 1976; Lévi-Strauss, 1976). O paradoxo desse diálogo de surdos é que Harris não parece ter percebido que a antropologia estrutural, longe de se satisfazer com um "mentalismo" soberbo, tal como ele a acusou, apoia-se, ao contrário, num naturalismo bem mais radical que aquele defendido pelos adeptos do determinismo geográfico. Porque, se é verdade que Lévi-Strauss nunca deixou de mostrar ostensivamente uma indiferença pelo que denominou, na linguagem de Marx, de "a ordem das infraestruturas", também nunca abandonou a convicção de que a natureza condiciona as operações intelectuais graças às quais a cultura recebe um conteúdo empírico, nem hesitou em antecipar o momento em que esta poderia ser interpretada em termos puramente orgânicos, como o resultado natural e o modo social de apreensão das modifi- 
cações de estrutura e de funcionamento do cérebro. Dessa dupla tendência resulta uma coabitação às vezes infeliz entre um programa científico formulado em termos classicamente dualistas - à etnografia, assistida pela história e pela tecnologia, o estudo da base material das sociedades; à antropologia estrutural, o estudo das ideologias - e uma teoria do conhecimento decididamente monista, visto que ela considera o espírito dando sentido ao mundo como parte e produto desse mesmo mundo.

A Conferência Gildersleeve oferece uma ilustração eloquente dessa combinação paradoxal. Recusando a oposição entre matéria e espírito, Lévi-Strauss afirmou que toda vida social é marcada por dois determinismos simultâneos e complementares: um, de tipo tecnoeconômico, impõe ao pensamento coerções resultantes da relação que a sociedade mantém com um meio particular; o outro reflete as exigências inerentes ao funcionamento do espírito e se manifesta sempre idêntico, independentemente das diferenças entre os meios. O primeiro determinismo exige que o etnólogo esteja informado das propriedades objetivas dos objetos naturais que o espírito vai selecionar em determinado contexto cultural para constituí-los em conjuntos significantes, tais como os mitos e as taxinomias. Logo, é imperativo conhecer bem a ecologia de uma sociedade se há a intenção de analisar suas produções ideológicas, pois elas são a prova de um compromisso entre certos traços do meio e as leis que organizam o pensamento simbólico. O próprio Lévi-Strauss sempre dedicou uma atenção minuciosa à flora, à fauna ou aos ciclos astronômicos e climáticos próprios das regiões de onde provêm os mitos que ele estudava; compreende-se que essa precaução metodológica lhe foi necessária para que estabelecesse com rigor como relatos de sociedades vizinhas utilizam características diferentes da ecologia local para preencher funções míticas equivalentes.

Entretanto, a antropologia estrutural é, antes de tudo, uma semiologia, e mesmo uma psicologia, e é sobre as manifestações do segundo tipo de determinismo, o determinismo mental, que o interesse de Lévi-Strauss se fixou, não para destacar universais cognitivos, mas para explicar a maneira como o espírito procede em contextos culturais e geográficos distintos, sofrendo em seu funcionamento o efeito de atração e de desvio que as peculiaridades e o ambiente físico e social lhe impõem. Por isso, Lévi-Strauss, fiel a seu projeto de fazer um inventário dos "recintos mentais" a partir da experiência etnográfica, deixou pouco a pouco o campo dos estudos sociológicos que ocuparam a primeira parte de sua carreira para se dedicar ao estudo das diferentes manifestações do pensamento mítico. Nada garante, com efeito, que as coerções que ele havia revelado nos sistemas de parentesco sejam de origem mental; talvez sejam apenas um reflexo na consciência dos homens de certas exigências da vida social objetivadas nas instituições. Por ser desprovida de função prática imediata, a mitologia não apresenta essa ambiguidade e revela ao analista, sob forma particularmente pura, as operações de um espírito já não condenado a 
pôr em ordem uma realidade que lhe é exterior, mas livre para compor consigo como por desdobramento.

Embora Lévi-Strauss afirmasse a simetria entre o determinismo mental e o determinismo do meio, ele não lhes concedeu peso igual em sua obra. De fato, o ambiente físico foi relegado a um papel subalterno, o de oferecer ao pensamento mítico a matéria com que se alimenta, função com certeza útil, mas da qual não se pode dizer que reflita plenamente o conjunto das interações possíveis de uma sociedade com seu meio geográfico. Assim, os materialistas não estão errados ao censurar Lévi-Strauss por sua falta de interesse pela incidência dos fatores ecológicos sobre todos esses aspectos da vida social que não podem ser considerados produtos da atividade simbólica. Não é esse o seu problema, já que ele tinha escolhido as "superestruturas", prosseguindo um estudo que Marx, afirmou ele, tinha apenas esboçado. Nesse estágio da divisão do trabalho antropológico, a natureza torna-se como um gigantesco reservatório de propriedades observáveis dentro do qual o espírito terá toda a possibilidade de vir colher objetos para convertê-los em signos. Em resumo, essa natureza enciclopédica é, sobretudo, "boa para pensar", trampolim de onde a imaginação taxinômica toma impulso, pretexto para as estranhas combinações que fazem a trama dos mitos, vasto e fecundo pressuposto da objetivação do mundo em enunciados codificados. Essa natureza plantada como um cenário para o teatro do espírito se opõe, decerto, à natureza maciça e implacável do determinismo geográfico; mas se opõe também à outra natureza cujos efeitos Lévi-Strauss costuma evocar, a natureza orgânica de nossa espécie, por meio da qual se efetua a percepção e a intelecção dos objetos sensíveis, o mecanismo biológico que garante a unidade das operações mentais e autoriza a esperança de decifrar-lhes as regras. Assim como a natureza externa ao homem permanece num papel subsidiário, assim também sua natureza corporal se vê privilegiada como pedra de toque de uma teoria das faculdades que recusa discriminar entre os estados da subjetividade e as propriedades do cosmos.

Lévi-Strauss estava bem consciente da contradição formada por essa dualidade de naturezas; por isso, procurou propor uma solução na qual se percebem ecos da fenomenologia de Merleau-Ponty. Nas últimas páginas da Conferência Gildersleeve, a natureza corporal aparece definida como um meio orgânico, homólogo ao meio físico, e tanto mais ligado a ele porque o homem só é capaz de se apropriar do segundo pela mediação do primeiro. Entre as informações transmitidas pelos órgãos dos sentidos, seu código cerebral, e o próprio mundo físico, é preciso, pois, que exista certa afinidade. Sobre o que se apoia essa afinidade? Sobre o fato, responde Lévi-Strauss, de os dados imediatos da percepção sensível não serem matéria bruta, uma espécie de cópia autêntica dos objetos apreendidos, mas consistirem em propriedades distintivas, abstraídas do real por mecanismos de codificação e de decodificação inscritos no sistema nervoso e que funcionam por meio de oposições binárias: contras- 
te entre movimento e imobilidade, presença ou ausência de cor, diferenças de contorno dos objetos... A estrutura não seria, portanto, puro produto do intelecto pondo livremente em forma uma realidade plástica; o espírito não cessa de trabalhar estruturalmente informações que ele recebe já estruturadas pela sensibilidade. Sem dúvida. Mas os órgãos dos sentidos, terão eles uma atividade estruturante ou uma atividade estrutural? Efetuam uma codificação dos estímulos por oposição de traços distintivos, ou se contentam com restituir uma codificação já presente na realidade exterior? Foi esta segunda opção que Lévi-Strauss escolheu sem hesitar quando afirmou que as propriedades estruturais da natureza não se distinguem em sua essência dos códigos por meio dos quais o sistema nervoso as decifra, nem das categorias das quais o entendimento se serve para explicar propriedades do real; enfim, "o espírito realiza operações que não diferem por natureza daquelas que acontecem no mundo" (Lévi-Strauss, 1976: 164-165). Nessa homologia de estrutura entre o signo e a coisa que ele denota, o processo de significação é, assim, remetido à natureza, a uma armadura binária da realidade objetiva que permite explicar e garantir o isomorfismo entre a linguagem e o mundo.

Ao adotar uma teoria fisicalista do conhecimento, Lévi-Strauss pôde então recusar o dualismo filosófico, continuando a executar um perfeito dualismo de método. Em suas análises de mitos, o ambiente físico não é tratado "em natura", isto é, como um conjunto de efeitos de causalidade, de propriedades estruturais e de agregados moleculares que seria codificado, decodificado e recombinado pelo mecanismo perceptivo e cognitivo. Seriam necessárias, para isto, ferramentas científicas que ainda estamos longe de possuir. A natureza exterior ao homem é convocada, sobretudo, como uma espécie de léxico de traços distintivos a partir do qual os órgãos sensíveis e o cérebro produziriam textos de acordo com uma sintaxe própria. E, se afinal a análise dos mitos é possível, será exatamente porque o léxico das naturezas não humanas varia em função dos ambientes com os quais cada cultura tem de compor, ao passo que a gramática natural do entendimento que organiza esses elementos em enunciados permanece, quanto a ela, invariante. Daí o paradoxo da antropologia estrutural, que faz de uma concepção monista do espírito e do mundo a legitimação de um método de análise no qual o relativismo natural - a variedade dos meios - tem um papel que, alhures, é atribuído ao relativismo cultural.

Lévi-Strauss não se converteu ao monismo tardiamente e sob a influência das neurociências, tal como a Conferência Gildersleeve poderia fazer supor. Tratava-se de uma intuição precoce que ele reformulou incansavelmente ao correr do tempo e que as descobertas da biologia vieram confirmar oportunamente, dando-lhe um impulso de legitimidade empírica. Desde Les structures élémentaires de la parenté [As estruturas elementares do parentesco], estava bem presente a ideia de que as raízes da cultura devem ser buscadas na natureza, nos princípios orgânicos de funcionamento do pensamento que não diferem 
das leis da realidade física e social. Mas essa profissão de fé estava formulada numa linguagem filosófica ainda tão tributária das categorias dualistas que muitos leitores apressados não perceberam que a distinção de princípio entre a natureza e a cultura pela qual o livro começa era apenas um artifício de exposição permitindo recusar qualquer oposição substantiva entre os dois domínios.

Lembremos rapidamente a demonstração. Por motivos talvez ligados em parte aos preceitos universitários da época, Lévi-Strauss achou conveniente introduzir sua tese por uma exposição genética: deixando de lado, momentaneamente, o espírito do método estrutural, ele procurou isolar um fundamento lógico no qual apoiar suas análises das instituições matrimoniais, um primeiro motor responsável por toda a dinâmica posterior da vida social. Essa base primitiva, como se sabe, é a proibição do incesto. Única regra universal, ela representa uma síntese originária na qual se expressa a passagem da natureza para a cultura: é natural, pois é evidente para toda a espécie humana; é cultural porque se expressa numa norma, variável em suas formulações, mas não no seu princípio. Verdadeira certidão de nascimento da vida social, a proibição do incesto funda a obrigação da troca das mulheres e expressa "a passagem do fato natural da consanguinidade para o fato cultural da aliança” (Lévi-Strauss, 1967: 35). Um corte irreversível parece assim instituído num momento indefinido do processo de hominização entre um estado natural desprovido de qualquer regra de comportamento e um estado cultural caracterizado pela exogamia e a reciprocidade na troca, condições primeiras das instituições matrimoniais que Lévi-Strauss começou a analisar.

Quem fizer uma leitura superficial dos capítulos iniciais sobre a metodologia em As estruturas elementares do parentesco vai, sem dúvida, reter esse dualismo exorbitante, essa virada súbita da natureza para a cultura, da qual, de Grotius a Rousseau, os teóricos do contrato social já haviam proposto a hipótese sem, com isso, atribuir-lhe a mínima verossimilhança histórica. Ora, a ideia de uma solução de continuidade tão radical é desmentida em vários trechos posteriores do livro, intercalados quase como por acaso entre desenvolvimentos técnicos sobre os sistemas de casamento. Lá se constata que a cultura só codifica determinações impostas pela natureza - o instinto sexual ou a aptidão para pensar as relações biológicas sob as formas de sistemas de oposição, ${ }^{1}$ e que ela o faz segundo esquemas cognitivos universais preexistentes às normas que os traduzem. Tais esquemas são espécies de imperativos categóricos inscritos na arquitetura do espírito - a exigência de regras, a noção de reciprocidade e o caráter sintético do dom (Lévi-Strauss, 1967: 98) -, estruturas formais, portanto, que constituem "[...] a base indestrutível das instituições matrimoniais e da proibição do incesto pela qual a existência dessas instituições se tornou possível, e da própria cultura, da qual a proibição do incesto constitui o advento" (Lévi-Strauss, 1967: 507). Ou seja, a proibição do incesto e o intercâmbio que ela instaura são causas eficientes da vida social, mas o movimento que anima 
esta vida social tem origem em limites biológicos e psicológicos mais fundamentais porque provenientes da natureza orgânica do homem. E, para escapar à dualidade da natureza humana e da natureza física que tal concepção poderia fazer supor, Lévi-Strauss não hesita, como conclusão do livro, em acolher Engels e sua Dialética da natureza, profetizando, como esse autor, que "[...] as leis do pensamento são as mesmas que se exprimem na realidade física e na realidade social, não sendo esta última outra coisa que um dos seus aspectos " (Lévi-Strauss, 1967: 520). O contraste nítido entre natureza e cultura afirmado no início de Estruturas elementares... era, portanto, uma ficção filosófica, um modo de experiência do pensamento sem implicação ontológica, mas que foi tomado ao pé da letra por muitos críticos, mesmo os mais perspicazes. ${ }^{2}$ Assim, para dissipar qualquer equívoco, Lévi-Strauss teve o cuidado de precisar, no prefácio à segunda edição, que a oposição entre cultura e natureza não é "[...] nem um dado primitivo, nem um aspecto positivo da ordem do mundo. Dever-se-ia ver nela uma criação artificial da cultura" (Lévi-Strauss, 1967: XVII, grifos meus).

Criação artificial, sem dúvida, mas também tardia e historicamente determinada. É o que convém acrescentar se dermos algum crédito ao que a etnografia revela das continuidades múltiplas entre humanos e não humanos, das quais cosmologias de tantas sociedades não modernas são a prova. Ora, não é a via que Lévi-Strauss parece seguir quando aborda as produções ideológicas dessas sociedades: nesse assunto, e ao contrário de sua própria advertência, ele tende a ceder à tentação de tratar a oposição entre natureza e cultura como "um dado primitivo" e "um aspecto positivo da ordem do mundo". Na análise estrutural dos mitos, de fato, ele distribui as propriedades, as substâncias e as entidades que ele isola na cadeia narrativa, no interior de matrizes contrastivas quase sempre ordenadas segundo o eixo dessa mesma oposição; como se, ao utilizar a antítese entre o cru e o cozido, o mel e o tabaco, os dejetos e os adornos, o fogo do mato e o fogo de cozinha, os inventores anônimos das narrativas míticas tivessem tido a intuição confusa de que esses pares de traços distintivos se repartiam de cada lado de uma dualidade mais fundamental, não percebida como tal, mas já presente na textura das coisas.

Ninguém contesta que certos contrastes são universalmente percebidos entre estados da matéria, propriedades dos seres ou características dos modos de ação e processos orgânicos, e que pares, tais como: cheio e vazio, flexível e rígido, alto e baixo, direito e esquerdo, vida e morte, quente e frio, ou continente e conteúdo, oferecem, em toda parte, uma trama física adequada para organizar sistemas simbólicos. Mas nada autoriza a pensar que a antinomia natureza e cultura tenha sido, antes da época moderna, uma maneira comum de estruturar alguns desses contrastes entre traços salientes do mundo, mesmo num nível implícito. É possível admitir, por exemplo, que nenhuma sociedade ficou indiferente aos diversos estados das substâncias alimentares e que o cru, o cozido, o podre ou o fervido fazem parte das categorias mentais, se não 
sempre lexicais, de que toda a humanidade soube fazer uso. Mas, deve-se, por isso, analisar essas categorias tomando como eixo principal a polaridade natureza/cultura, como fez Lévi-Strauss com espantosa virtuosidade em Le triangle culinaire [O triângulo culinário] (Lévi-Strauss, 1965). Convém lembrar que, para ele, o assado estaria universalmente do lado da natureza, e que o fervido estaria do lado da cultura, sob o pretexto de que o primeiro se aproxima do cru, por nunca ficar igualmente cozido, ao passo que o segundo, exigindo o uso de um recipiente e a mediação da água, provaria um grau mais avançado de civilização? Ora, se a conquista do fogo marca o advento da humanidade à cultura, como Lévi-Strauss procurou mostrar ao longo das Mythologiques [Mitológicas], então nada autoriza a dizer que o assado seria menos cultural que o fervido, pois a distinção entre natureza e cultura não pode admitir gradações, sob pena de despojar a antinomia de sua pertinência e de seu poder operatório. Tanto mais porque o eixo natureza/cultura está longe de esgotar todos os contrastes entre o fervido e o assado, contrastes que o próprio Lévi-Strauss evoca em seu artigo: cozimento interno versus cozimento superficial (dentro/fora), consumo familiar versus refeição festiva (endocuisine/exocuisine), cozinha feminina versus cozinha masculina, conservação das carnes e dos sucos versus desperdício (economia/ prodigalidade), cozinha em casa versus cozinha fora de casa etc.

Ao introduzir a oposição entre natureza e cultura como uma das dimensões maiores de sua análise dos modos culinários, Lévi-Strauss se expõe ainda a terríveis dificuldades lógicas quando é preciso articular o assado e o fervido com o podre e o defumado. O fervido e o podre apresentam, de fato, afinidades que muitas línguas não deixaram de notar; ora, na "chave" natureza/cultura para retomar uma metáfora de Lévi-Strauss - o fervido é a forma mais cultural de preparação culinária, ao passo que o podre é a elaboração natural de uma categoria natural, ou seja, o cru. Por que então a cerâmica, invenção cultural por excelência, acabou gerando um tipo de alimento, o fervido, que se assimila mais ao podre, isto é, ao estado que os alimentos não cozidos atingem espontaneamente? Contradição análoga afeta o defumado. Trata-se do modo de cozimento que, segundo Lévi-Strauss, mais se aproxima do cozido e, portanto, do ponto ótimo de cultura. Ora, entre as populações ameríndias, a grelha de varas que serve para moquear as carnes deve ser destruída após o uso, ao contrário do que ocorre com o cozimento por ebulição, cujos recipientes são cuidadosamente conservados. O resultado é que defumar, a forma mais cultural de preparação dos alimentos, supõe a anulação do meio cultural que a tornou possível, ao passo que o modo de cozimento no qual um dos mais fortes símbolos da cultura é utilizado tem como resultado um produto que tende para o natural. Longe de permitir distribuir propriedades, estados e processos num campo de oposição e de correspondências simétricas, a dicotomia natureza/cultura introduz aqui inversões e contiguidades paradoxais. 
A solução adotada por Lévi-Strauss para resolver tais paradoxos consiste em afirmar que a oposição entre natureza e cultura se dissolve quando é mediatizada pela cozinha: “Tudo acontece como se a posse durável de uma aquisição cultural provocasse [...] uma concessão feita como contrapartida à natureza: quando o resultado é durável, o meio deve ser precário, e vice-versa" (Lévi-Strauss, 1965: 27). Isto é, a conservação dos alimentos obtidos por defumação é durável porque o meio - o moquém - é precário, ao passo que a conservação dos alimentos cozidos é precária porque o meio - os recipientes - é durável. A cozinha articula, portanto, a natureza e a cultura desdobrando e invertendo qualidades e estados que decorrem desses dois domínios, à custa de uma inelutável assimetria. Mesmo que se admita com Lévi-Strauss que a assimetria é o preço a pagar para que a estrutura dê ao mito seu dinamismo, cabe indagar se a elegante demonstração do "triângulo culinário" não poderia ter sido feita sem utilizar o eixo natureza/cultura. Em vez de partir de uma oposição cuja análise mostra que ela não recorta dois campos de predicados nitidamente diferenciados, por que não se limitar a sistemas de contrastes expressando propriedades fenomenais da matéria e da ação? Esses contrastes, aliás, o próprio Lévi-Strauss propõe e utiliza: a distinção entre elaborado e não elaborado, ou entre processo espontâneo e processo provocado, a gama de mediações possíveis entre o alimento e aquilo que o transforma (o fogo, o ar, a água, a gordura), o tipo de instrumento de cozimento (chato, côncavo, convexo, aberto, fechado...) e o grau de imersão num líquido etc. Tudo isso oferece uma série de combinações que permitem explicar o conjunto dos modos culinários e dos significados que lhes são ligados, sem apelar para uma distinção de tipo ontológico da qual nada indica que ela seja universalmente compartilhada.

Em vários momentos, sobretudo em Mitológicas, Lévi-Strauss parece assim obrigado a artifícios analíticos por dar um valor demasiado literal e substantivo a uma oposição entre natureza e cultura à qual a matéria de que ele trata parece estranha. É o caso, por exemplo, de sua análise das relações entre doenças e venenos de pesca e de caça na mitologia sul-americana (Lévi-Strauss, 1964: 279-287). O veneno é aí definido por Lévi-Strauss como um ponto de isomorfismo entre natureza e cultura, visto que se trata, segundo ele, de uma substância natural que permite uma atividade cultural. No entanto, o curare e muitos outros venenos ameríndios resultam de uma preparação longa e complexa que exige jejuns, interditos sexuais e múltiplas precauções. No momento em que são usados, na caça ou na pesca, já não são "substâncias naturais" e, sim, produtos da atividade humana resultantes de uma transformação técnica. Além disso, o curare é objeto de trocas intertribais intensas e muito antigas, assim como outros bens altamente valorizados, como as armas, os utensílios, os adornos e o sal. Se o sal e o curare figuram nessas trocas, é por causa das transformações que sofreram durante sua confecção: são pensados a exemplo dos outros produtos artesanais, e não como matérias-primas. Note-se, enfim, 
que a definição dos venenos dada por Lévi-Strauss pode ser aplicada do mesmo modo a todos os artefatos produzidos pelos ameríndios: uma sarabatana, um arco, uma cerâmica, um adorno, até uma casa, são mesmo, como os venenos, o resultado da transformação de substâncias naturais desempenhando, ao final de sua elaboração, uma função cultural. Ora, jamais Lévi-Strauss considera os artefatos como mediações de natureza e de cultura; ao contrário, utiliza-os muitas vezes como símbolos da cultura opostos às substâncias naturais. $\mathrm{Da}$ argila à cerâmica, por exemplo, da qual se poderia pensar que é, por excelência, uma substância natural que vem desempenhar uma função cultural, ele escreve que ela constitui "[...] uma das matérias-primas da cultura", e por isso é oposta nos mitos à argila dos cupinzeiros, símbolo da natureza (Lévi-Strauss, 1964: 254). Por que reconhecer na argila o que é negado aos peixes, e inversamente?

A explanação sobre os venenos de caça e de pesca se integra em uma análise, no caso magistral, em que Lévi-Strauss expõe a dialética dos pequenos e grandes intervalos existentes no pensamento mítico ameríndio. Segundo ele, os venenos são entidades "cromáticas", porque realizam uma transitividade insensível da natureza para a cultura, mantendo ao mesmo tempo efeitos "diatônicos", pois causam estragos entre os animais, que são as principais vítimas: um contínuo máximo gera assim um descontínuo máximo. A hipótese é fecunda, mas não é preciso convocar a natureza e a cultura para mostrar que os venenos fazem parte do contínuo. Algumas de suas propriedades intrínsecas podem também atestar isso. Assim, o veneno de pesca se dissolve aos poucos na água, produzindo um lençol que deriva ao sabor da corrente; uma vez imerso, não tem limites definidos e sua presença visível depende do seu grau de diluição: ele é, portanto, bem "cromático". Quanto aos venenos de caça, alguns permanecem virulentos durante um período muito longo; tal duração de conservação, que ultrapassa a da maioria dos artefatos produzidos pelos índios, predispõe, sem dúvida, estas substâncias tóxicas, sempre utilizadas em quantidades ínfimas, a se tornarem símbolos perfeitos do contínuo. Convém acrescentar que o curare que, quando frio, se apresenta sob a forma de uma pasta sólida, torna-se líquido quando é esquentado para untar os projéteis: logo, ele é "cromático" também, pois atravessa vários estados segundo gradações insensíveis. Diferentemente da "natureza" e da "cultura", abstrações filosóficas dificilmente transponíveis fora de seu contexto de origem, todas essas propriedades físico-químicas dos venenos são bem conhecidas dos ameríndios e, portanto, exploráveis na lógica do concreto que seus mitos formam e dos quais Lévi-Strauss retraçou admiravelmente as articulações.

Porque, se há um domínio em que a distinção natureza/cultura não funciona é o dos mitos ameríndios, estas histórias insólitas de uma época em que humanos e não humanos não eram diferenciados, época em que, tomando exemplos jívaros, era normal que curiango cozinhasse, que grilo tocasse sanfona, que colibri lavrasse os roçados ou que pedreiro caçasse com a sarabatana. 
Naquele tempo, de fato, animais e plantas dominavam as artes da civilização, comunicavam-se entre si sem problema e seguiam os grandes princípios da etiqueta social. Pelo que se sabe, sua aparência era humana, e só alguns indícios - seu nome, comportamentos estranhos - anunciavam aquilo em que iriam se transformar. De fato, cada mito relata as circunstâncias que redundaram em mudança de forma, na atualização de um corpo não humano de um animal ou de uma planta que, antes, existia em estado de potencialidade. A mitologia jívaro assinala, aliás explicitamente, essa mudança de estado físico, destacando o remate da metamorfose pelo aparecimento de um traço anatômico ou pela emissão de uma mensagem sonora característicos da espécie. Os mitos ameríndios não evocam, portanto, a passagem irreversível da natureza para a cultura, mas, sim, a emergência das descontinuidades "naturais" a partir de um continuum "cultural" de origem, dentro do qual humanos e não humanos não eram distinguidos com nitidez. Esse grande movimento de especiação não chegou mesmo a constituir uma ordem natural idêntica àquela que conhecemos, visto que, se as plantas e os animais passaram a ter fisicalidades diferentes da dos humanos - e, portanto, dos hábitos que correspondem ao equipamento biológico próprio de cada espécie -, também a maioria deles conservou, até os dias de hoje, as faculdades interiores de que gozavam antes de sua especiação: subjetividade, consciência reflexiva, intencionalidade, aptidão a se comunicar numa linguagem universal etc. São, portanto, pessoas, recobertas por um corpo animal ou vegetal do qual elas se despem em determinados momentos para levar uma vida coletiva análoga à dos humanos: os Makuna, por exemplo, dizem que as antas se pintam com urucum para dançar e que os caititus tocam a tromba durante seus rituais, ao passo que os Wari pretendem que o caititu faz cerveja de milho e que a onça leva a presa para casa a fim de que sua esposa a cozinhe. ${ }^{3}$

Durante muito tempo tomou-se esse tipo de enunciado como prova de um pensamento rebelde à lógica, incapaz de distinguir o real do sonho e dos mitos, ou como simples figuras de linguagem, metáforas ou jogo de palavras. Mas os Makuna, os Wari e muitos outros povos ameríndios que pretendem esse tipo de coisas, não são mais míopes ou crédulos que nós. Sabem muito bem que a onça devora sua presa crua e que o caititu mais devasta do que cultiva as plantações de milho. São a onça e o caititu, afirmam eles, que se percebem como realizando gestos idênticos aos dos humanos, que se imaginam com naturalidade partilhando com estes últimos o mesmo sistema técnico, a mesma existência social, as mesmas crenças e aspirações. Em resumo, nos mitos, como na existência cotidiana, os ameríndios não veem o que nós chamamos de cultura como o apanágio dos humanos, visto que muitos são os animais, e até mesmo as plantas, que são tidos como possuindo e vivendo segundo suas normas. Torna-se então difícil atribuir a esses povos a consciência ou o pressentimento de uma distinção entre natureza e cultura homóloga àquela que nos é familiar, coisa que tudo em seus modos de pensar parece desmentir. 
Apesar de advertir que tal distinção não deveria ser considerada de modo excessivamente literal, Lévi-Strauss nem sempre conseguiu fugir da tentação de ver nela um dado universal da experiência humana. Mas não estará esta crítica além do necessário? Primeiro, porque a informação etnográfica de que Lévi-Strauss dispunha há 40 anos, época em que redigiu sua tetralogia, era ainda muito imprecisa e lacunar, limitando-se praticamente à coleta de mitos. As pesquisas intensivas feitas a partir de então sobre os índios da América do Sul revelaram perspectivas inéditas sobre as cosmologias e os modos de pensar que o autor das Mitológicas não pôde levar em conta na época. Sobretudo, a impressão é que Lévi-Strauss utiliza o binômio natureza/cultura na análise dos mitos como uma espécie de etiqueta genérica, ou de atalho semântico, e não como uma verdadeira antinomia expressando uma dimensão intrínseca da apreensão do mundo. Seria como uma designação abreviada que ajudava a condensar, sem muitos circunlóquios, conjuntos contrastados de qualidades e de estados que os povos, cujos mitos ele estudava, distinguem de fato, sem sentirem a necessidade de distribuí-los entre dois polos nitidamente diferenciados. Foi o caso, já vimos, da intuição muito fecunda de que os venenos amazonenses têm caráter "cromático" e efeitos "diatônicos", embora seja impossível referi-los a rubricas ontológicas contrastadas sem violentar as concepções locais dessas substâncias. Esse uso, em grande parte tipológico, da oposição entre natureza e cultura explica, aliás, porque os etnólogos da América indígena são unânimes em aclamar o alcance heurístico das conclusões etnográficas que Lévi-Strauss tirou de suas análises dos mitos, mesmo quando eles duvidam da pertinência de tal oposição para as sociedades com que estão habituados a trabalhar.

Se me detive nesse aspecto da obra de Lévi-Strauss, foi porque ele é muitas vezes considerado, sobretudo pela antropologia anglo-saxônica, o principal defensor de um dualismo sem nuanças e ponto de chegada de uma corrente intelectual que, nascida com Descartes e identificada ao racionalismo francês, teria insistido em dissociar natureza e cultura, corpo e espírito, intelecto e sentimentos, reificando de cambulhada o pensamento e as instituições dos povos sem escrita com a ajuda de oposições binárias, tão abstratas quanto inverificáveis. Cabia refutar essa caricatura, que se tornou credo dominante nos Estados Unidos, apontando ao mesmo tempo as ambiguidades de certas formulações de Lévi-Strauss, que deram origem a mal-entendidos para os leitores. Porque, quem desejar exemplos do emprego literal da oposição natureza/cultura não deve procurá-los em Lévi-Strauss e sim nos autores que foram influenciados por ele, aplicando como receitas certos procedimentos elementares da análise estrutural sem medir de fato a que ponto ela era inseparável de uma teoria monista do conhecimento que anulava, em parte, o dualismo do método. 
É verdade também que a posição de Lévi-Strauss nesse campo mostra dificuldades que a antropologia encontra por causa de sua adesão mais ou menos explícita à crença de que o mundo pode ser distribuído entre dois campos de fenômenos isolados cuja interdependência deve ser mostrada. Apreendidos em suas formulações mais excessivas, os termos da discussão tornam qualquer mediação impossível: ou a cultura é modelada pela natureza, seja esta feita de genes, de instintos, de redes de neurônios ou de coerções geográficas, ou então a natureza só assume forma e relevo como um reservatório potencial de signos e de símbolos no qual a cultura vem buscar alimento. Certamente entre "o determinismo crasso" e a "imaginação aérea", segundo as expressões de Augustin Berque, muitos autores - antropólogos, geógrafos, filósofos - tentaram encontrar uma via média, uma saída dialética que permitisse escapar ao confronto de ambos os dogmatismos (Berque, 1986: 135 e 141). A igual distância dos positivistas militantes e dos defensores de uma hermenêutica sem concessões, eles tentam acoplar o ideal e o material, o concreto e o abstrato, as determinações físicas e a produção do sentido. Mas tais esforços de mediação são condenados à ineficácia, seja porque se apoiam nas premissas de uma cosmologia dualista, seja porque presumem a existência de uma natureza universal que múltiplas culturas codificam ou à qual se adaptam. No eixo que leva de uma cultura totalmente natural a uma cultura totalmente cultural, não se poderia encontrar um ponto de equilíbrio, e sim apenas compromissos mais próximos de cada um dos polos. Aliás, o problema é tão antigo quanto a própria antropologia; no dizer tão claro de Marshall Sahlins, ela é como um prisioneiro obrigado há mais de um século a andar dentro de uma cela, confinado entre o muro das coerções do espírito e o das determinações práticas (Sahlins, 1976: 55).

Admito que esse tipo de prisão tem vantagens. O dualismo não é um mal em si e seria ingênuo estigmatizá-lo por motivos puramente morais, como fazem filosofias ecocêntricas do meio ambiente, ou de atribuir-lhe a responsabilidade de todos os males da era moderna, desde a expansão colonial até a destruição dos recursos não renováveis, passando pela reificação das identidades sexuais ou das distinções de classe. Deve-se, no mínimo, ao dualismo, com a aposta de que a natureza está sujeita a leis próprias, um formidável estímulo ao desenvolvimento das ciências. A ele também se deve, com a crença de que a humanidade se civiliza pouco a pouco por controlar cada vez mais a natureza e disciplinar cada vez melhor seus instintos, certas vantagens, sobretudo políticas, que a aspiração ao progresso conseguiu gerar. A antropologia é filha desse movimento, do pensamento científico e da fé na evolução, e não há porque envergonhar-se das circunstâncias de seu nascimento, nem desejar que ela desapareça para expiar os pecados da juventude. Mas seu papel se acomoda mal com essa herança; consiste em compreender como povos que não partilham nossa cosmologia puderam inventar para si realidades distintas da nossa, demonstrando assim uma criatividade que não pode ser medida pelos critérios de 
nossas realizações. Ora, é o que a antropologia não pode fazer quando considera adquirida como um dado universal da experiência humana a nossa realidade, nossas maneiras de estabelecer descontinuidades no mundo e de nelas descobrir relações constantes, nossos modos de distribuir entidades e fenômenos, processos e modos de ação, em categorias que seriam predeterminadas pela textura e pela estrutura das coisas.

Decerto não apreendemos as outras culturas como análogos completos da nossa - seria inverossímil. Temos é a tendência de vê-las através do prisma de apenas uma parte de nossa cosmologia, como expressões singulares da cultura enquanto ela contrasta com uma natureza única e universal, culturas muito diversas, portanto, mas que correspondem todas ao cânon constitutivo do que nós entendemos por essa dupla abstração. Por estar profundamente arraigado em nossos hábitos, esse etnocentrismo é dificílimo de extirpar: para a maioria dos antropólogos, como Roy Wagner assinala com exatidão, as culturas periféricas do Ocidente moderno "[...] não oferecem contrastes, ou contraexemplos, à nossa cultura, como sistema total de conceptualização; o que elas sugerem são comparações quanto a 'outras maneiras' de tratar nossa própria realidade" (Wagner, 1981: 42). Fazer do dualismo moderno da natureza e da cultura a medida de todos os sistemas do mundo é obrigar-nos a uma espécie de canibalismo indulgente, uma incorporação repetida da objetivação dos pré-modernos por eles mesmos na objetivação de nós por nós mesmos. Por muito tempo considerados radicalmente outros, e utilizados por isso como espantalhos da moral cívica ou modelos de virtudes desaparecidas, os selvagens passam a ser vistos como vizinhos quase transparentes, já não aqueles "filósofos nus" elogiados por Montaigne, mas esboços de cidadãos, protonaturalistas, quase-históricos, economistas em gestação, enfim, precursores tateando em busca de uma maneira de apreender as coisas e os homens que teríamos sabido revelar e codificar melhor que ninguém. Eis uma maneira de homenageá-los, com certeza, mas também o melhor meio, se os assimilarmos ao nosso destino, de fazer desaparecer sua contribuição à inteligibilidade da condição humana.

Artigo recebido para publicação em julho de 2011.

Philippe Descola é professor e diretor do Laboratoire d'Anthropologie Sociale do Collège de France, e diretor de estudos na École des Hautes Études en Sciences Sociales (EHESS). Publicou La nature doméstique (1986), As lanças do crepúsculo (1993) e Par-delà nature et culture (2005). Seu tema principal de reflexão são as relações entre natureza e cultura. 


\section{NOTAS}

Este artigo foi originalmente publicado em Cahier de l'Herne: Lévi-Strauss, 2004, 82, p. 296-304. Agradecemos ao autor e a Éditions de l'Herne, que gentilmente permitiram a reprodução do artigo em português (N. E.).

1 “[...] as mulheres não são, em primeiro lugar, um signo de valor social, mas um estimulante natural ; e o estimulante do único instinto cuja satisfação pode ser diferida: o único, por conseguinte, para o qual, no ato de troca, e pela apercepção da reciprocidade, a transformação possa operar do estimulante ao signo, e, definindo por esse procedimento fundamental a passagem da natureza à cultura, desenvolver-se em instituição" (Lévi-Strauss, 1967: 73); “Mas se é verdade - como tentamos aqui demonstrar - que a passagem do estado de natureza ao estado de cultura se define pela aptidão, da parte do homem, para pensar as relações biológicas sob a forma de sistemas de oposição [...]" (Lévi-Strauss, 1967:158).

2 Ver Leach (1970: 112). Erro que Yvan Simonis não comete em sua excelente análise do naturalismo de Lévi-Strauss (Simonis, 1968: 33-67).

3 Para os Makuna, ver Ärhem (1990: 108-115); para os Wari, ver Vilaça (1992: 55-63).

\section{REFERÊNCIAS BIBLIOGRÁFICAS}

Ärhem, Kaj. Ecosofía Makuna. In: Correa, François (org.). La selva humanizada: ecologia alternativa en el trópico húmedo colombiano. Bogotá: Instituto Colombiano de Antropologia, 1990, p. 105-122.

Berque, Augustín. Le sauvage et l'artifice: les japonais devant la nature. Paris: Gallimard, 1986.

Harris, Marvin. Lévi-Strauss et la palourde: réponse à la Conference Gildersleeve de 1972. L'Homme, 1976, XVI/2-3, p. 5-22.

Leach, Edmund. Lévi-Strauss. Londres: Fontana/Collins, 1970. Lévi-Strauss, Claude. Mythologiques. Paris: Plon, 1964 (Vol. I: Le cru et le cruit). . Le triangle culinaire. L’Arc, 1965, 26, p. 1929. 
. Les structures élementaires de la parenté. Paris/Haye: Mouton et Co., [1949] 1967.

. Structuralism and Ecology. Conferência republicada no Le regard éloigné. Paris: Plon, [1972] 1983, p. 143-166.

. Anthropologie structurale deux. Paris: Plon.

. Structuralisme et empirisme. L'Homme, 1976, XVI/2-3, p. 23-38.

Sahlins, Marshall. Culture and practical reason. Chicago/Londres: The University of Chicago Press, 1976.

Simonis, Yvan. Claude Lévi-Strauss ou la "passion de l'inceste": introduction au structuralisme. Paris: Aubier-Montaigne, 1968. Vilaça, Aparecida. Comendo como gente: formas do canibalismo wari. Rio de Janeiro: Ed. UFRJ, 1992.

Wagner, Roy. The invention of culture. Chicago/Londres: The University of Chicago Press, [1975] 1981. 


\section{Palavras-chave: Resumo:}

Lévi-Strauss; Natureza;

Cultura; Dualismo natureza

e cultura; Estruturalismo

\section{Keywords: Abstract:}

Lévi-Strauss; Nature;

Culture; Nature and culture dualism; Structuralism.
Aborda-se aqui a complexidade do status do par conceitual natureza e cultura no pensamento de Lévi-Strauss. Ao mesmo tempo ferramenta de análise, cena filosófica dos primórdios e antinomia a superar, revisita-se os diferentes usos e significados na obra de Lévi-Strauss do conceito de natureza e sua relação com o de cultura. Mostra-se como é possível reconhecer na obra de Lévi-Strauss dois conceitos de natureza: por um lado, uma natureza que se opõe à cultura num programa científico formulado em termos classicamente dualistas e, por outro, uma teoria do conhecimento decididamente monista que considera o espírito como parte e produto desse mesmo mundo. Argumenta-se que se o dualismo entre cultura e natureza fundou o pensamento estruturalista de Lévi-Strauss, é na própria obra deste que encontramos os argumentos e meios de superá-lo. A vocação do estruturalismo na antropologia de hoje, no entanto, é de ir mais longe neste caminho do que foi o próprio fundador.

The paper address the complexity of the status of the conceptual pair nature and culture in Lévi-Strauss' thought. At the same time analysis tool, early philosophical scene and antinomy to be overcome, one revisits different uses and meanings in Lévi-Strauss' work of the concept of nature and its relationship with the one of culture. It is shown how it is possible to recognize in Lévi-Strauss' work two concepts of nature: on the one hand, a nature that is opposite to culture in a scientific program classically formulated in a dualistic way and, on the other, a decidedly monistic theory of knowledge that considers the spirit as part and product of this same world. It is argued that if dualism between culture and nature founded the structuralist thought of Lévi-Strauss, it is in his own work that one finds the arguments and means to overcome it. The vocation of structuralism in current anthropology, however, is to go further than its founder. 